\title{
Assessment of Knowledge and Attitude Regarding Risk Factors of Cardio Vascular Disease Among General People Residing in Nepalgunj, Banke; Nepal
}

Ramesh Prasad Tharu ( $\sim$ rameshpt02@gmail.com)

Lecturer, Tribhuvan University, Kathamandu, Department of Statistics, Mahendra Multiple Campus, Nepalgunj, Banke; Nepal https://orcid.org/0000-0002-8606-9185

Shirya Rawal

Bheri Nursing College, Purbanchal University,Nepal

\section{Research}

Keywords: Knowledge, Attitude, Risk factors, Cardio vascular disease (CVD), General people

Posted Date: November 5th, 2020

DOl: https://doi.org/10.21203/rs.3.rs-101221/v1

License: @ (i) This work is licensed under a Creative Commons Attribution 4.0 International License. Read Full License 


\section{Abstract}

Background: Cardio vascular disease (CVD) is a group of disorders of heart and blood vessels. It is the leading cause of death not only in developed but also in developing countries like Nepal. However, knowledge and attitude about risk factors of CVD have not yet studied in mid-western part of Nepal. Therefore, this study aimed to assess the level of knowledge and attitude regarding risk factors of CVD among general people residing in Nepalgunj, Banke; Nepal.

Methods: A community-based cross-sectional study was conducted. The pre-tested structured and selfadministered questionnaires were used to collect the data during the month of July to August 2019, and analysed using SPSS software version 21. The descriptive analysis was performed using frequencies, percentage, mean SD. Chi-square test and multinomial logistic regression (MNLR) analysis were used to identify the statistically significant factors associated with knowledge and attitude.

Results: Of total 150 subjects, $23.3 \%, 40.7 \%$ and $36.0 \%$ of the respondents respectively had good, average and poor knowledge. Likewise, $51.3 \%$ had unfavourable, $36.0 \%$ neutral and $12.7 \%$ favourable attitude towards risk factors of CVD. MNLR analysis revealed that education, gender and profession were significant predictor variables in association with the level of CVD knowledge and attitude: illiterates were $67 \%$ less likely (AOR = $0.330,95 \% \mathrm{Cl}: 0.117-0.929, \mathrm{P}=0.036<0.05)$ to have good knowledge about risk factors of CVD compared with literates. Participants having government jobs were 12.673 times more likely $(A O R=12.673,95 \% \mathrm{Cl}$ : $1.475-108.884, \mathrm{P}=0.021<0.05)$ to have good knowledge compared to those participants involving in agriculture. Males were $69.9 \%$ less likely $(A O R=0.301,95 \% \mathrm{Cl}: 0.140-0.648, P=0.002<0.05)$ to have unfavourable attitude in comparison to female over neutral attitude, and illiterates were 4.158 times more likely $(\mathrm{AOR}=4.158,95 \% \mathrm{Cl}: 1.707-10.128, \mathrm{P}=0.002<0.05)$ to have unfavourable attitude more than literates.

Conclusion: The findings of the study concluded that, the knowledge about CVD was adequate among general people, however the attitude was unfavourable. Thus, health awareness campaigns such as NTCP, DMP, MMMP needs to be implemented to develop knowledge and improve in attitude about risk factors of CVD.

\section{Introduction}

The Cardiovascular diseases (CVDs) are group of disorders of the heart and blood vessels and they include coronary heart disease, cerebrovascular diseases, deep vein thrombosis and pulmonary embolism and some other disorders of heart [1]. Around 17.9 million people died from CVDs in 2016, representing $31 \%$ of all global deaths. Among these three-quarters of CVD deaths take place in low and middle-income countries. According to the WHO data published in 2017, coronary heart disease (CHD) deaths in Nepal reached $18.72 \%$ of total deaths [2]. CVDs are the leading cause of deaths in both developed and developing countries. In $2008,30 \%$ (17.5 million people) of global all-cause mortalities were from CVDs. Of these, 6.2 and 7.3 million were due to stroke and $\mathrm{CHD}$ respectively. It is expected to increase to 23.3 million by 2030 [3]. By the heart disease and stroke statistics 2019, CVD remains the leading cause of death in United States, responsible for 840,768 deaths in 2016 but from 2006 to 2016, the US death rate from CVD decreased by $18.6 \%$ and from CHD by 31.8\% [4]. CVD mortality rates in the South Asian countries are much higher than the East Asian countries [5]. South Asian countries have an increasing trend of risk factors for $\mathrm{CHD}$ along with their economic development 
[6]. The South Asian countries like Nepal, India, Pakistan, Sri-Lanka and Bangladesh contribute most to the worldwide CVDs burden [7]. In Nepal, it is estimated that $5.6 \%$ of people living in the mountains, $1.5 \%$ in the hills and $5 \%$ of people in the Terai region suffer from CVDs [8]. That's why; CVDs are the leading causes of death globally including Nepal $[2,3,4,8]$. In Nepal, the estimated age-standardized death rates caused by CVD (Ischemic Heart Disease and Cerebrovascular Diseases) are 152 and 82 per 100,000 population respectively in 2008 [9].Moreover,13.8\% of industrial workers of Nepal were diagnosed with CVD in 2016 [10]. The deaths due to Non Communicable Diseases (NCDs: CVD, diabetes, cancer and respiratory disease) have increased from $60 \%$ in 2014 to $66 \%$ of in 2018 of all deaths in Nepal [11].

According to Texas Heart Institute (THI) the main risk factors for CVDs are hypertension, cigarette smoking, high fat level, diabetes, obesity and physically inactive and the minor risk factors contain stress due to anxiety, sex hormone intake, birth-control pills and alcohol drinking [12]. Furthermore, the major modifiable risk factors are tobacco smoking, physical inactivity, unhealthy dietary intake, high cholesterol and stress, eating fast food and carbonated drinks and non-modifiable risk factor are Age, family history, sex, ethnicity [12, 13]. As Surgeon General's Report on smoking and health in 2014, smoking is a major cause of CVD and causes approximately one of every four deaths from CVD. Also, exposure to second hand smoke causes heart disease in nonsmokers. More than 33,000 non-smokers die every year in the United States from CHD caused by exposure to second hand smoke. [14]. According to WHO, smoking, harmful use of alcohol, physical inactivity, unhealthy diets, obesity, hypertension, diabetes and hyperlipidemia are the established risk factors of CVDs. Smoking is estimated to cause nearly ten per cent (10\%) of all CVDs followed by physical inactivity (6\%), and overweight and obesity (5\%). Also, low fruits and vegetables intakes caused death of approximately 16 million people [15, 16]. National NCD risk factors survey 2013 detected considerably high proportions of smoking (18.5\%), alcohol consumption (17.4\%), insufficient fruits and vegetables consumption (98.9\%) and obesity (4\%) among Nepalese [17]. It is emerging as a major killer even in Nepal where mortality attributed to CVD has swiftly increased from $22 \%$ to $25 \%$ between 2004 and 2008. Most CVDs share common risk factors like tobacco use, physical inactivity, unhealthy diet, harmful use of alcohol, diabetes, high blood pressure and raised lipid. Among them, behavioural risk factors unhealthy diet, physical inactivity, tobacco use and harmful use of alcohol, alone contribute $80 \%$ of $\mathrm{CHD}$ and cerebrovascular disease $[12,13,18]$. There are several risk factors contributing to hypertension, such as age, gender and ethnicity. It is common in men over 45 years and women over 55 years. Positive family history being overweight and obese, particularly type 2 diabetes, are also additional risk factors. Other life style factors that contribute to hypertension are smoking, stress cell phone use and physical inactivity, consumption of alcohol, increase salt intake reduce potassium take $[19,20]$. STEPS survey of Nepal in 2013 detected hyper cholesterol in $23.0 \%$, smoking in $19.0 \%$, overweight in $21.0 \%$, raised blood glucose in $4.0 \%$, physical inactivity in 3.0\%, and harmful use of alcohol in 2.0\% [21]. In Nepal, hypertension was the most prevalent risk factor for CVD which ranged from $26.0 \%$ to $38.9 \%$. [22]. Nepal's high prevalence of underlying behavioural risk factors, particularly tobacco and alcohol consumption and poor cardiovascular health knowledge, is a matter of concern.[23].

CVD is the one of the major health problems in the developed and developing countries as well and is the one of the most cause of death globally [3]. It has gained worldwide attention and this is noted as one of the major challenges in the public health; there is a pressing need to study the trend of attitude and knowledge. Thus, it is necessary to recognize knowledge and attitude about this issue in order to make plans for medical 
challenge and to reduce the future burden of CVD in general people of Nepal. Despite the rising prevalence of CVDs and their associated risk factors in Nepal, a few published studies have been done on the issue in different part of Nepal $[32,39,40]$ but there are no published studies that have comprehensively assessed knowledge and attitude of CVDs and their risk factors in general people in the mid-western part of Nepal yet. This study, therefore, has attempted to assess the knowledge and attitude regarding risk factors of CVD among general people residing in Nepalgunj, Banke; Nepal.

\section{Methods}

\subsection{Study Design and Area}

A community based, cross sectional research design was adopted and the study was conducted in Dhamboji1, Nepalgunj; Banke, Nepal dated in July to August 2019. Nepalgunj is a sub- metropolitan city in Banke District, which is located in the Province number 5, the mid-western part of Nepal. According to 2011 census, the total population of Banke district had 491,313. Our study area was Dhomboji-1, the heart of the city and the study population comprised of all the people residing Dhomboji-1, Nepalgunj, Banke, was 10,000 and 2100 households. A sample of 150 people was selected using non-probability convenience sampling technique. Face to Face questionnaire on paper based interviews were conducted to collect the data. Information collected during interviews included socio-demographic characteristics, knowledge and attitude of risk factors for CVD.

\subsection{Sample Selection Criteria}

\section{Inclusion Criteria}

The study has included the general people having age between 20 to 60 years residing in Dhamboji-1, Nepalgunj; Banke and who

- were willing to participate in the study.

- were available at the time of data collection

\section{Exclusion criteria}

- General people residing Banke, who were not willing to participate in the study.

\subsection{Data collection tools}

The tools developed and used for data collection were pre-tested structured and self-administered questionnaire and Likert scale consisting of three parts: (i) Performa to collect socio-demographic data, (ii) structured knowledge questionnaire regarding risk factors of CVD and (iii) Likert scale to assess the attitude regarding risk factors of CVD. Further, the tool which consisted of socio-demographic data, structured knowledge questionnaire and attitude scale consisted of 11, 15 and 20 items (statements or questions) respectively. The knowledge score was classified into three categorized as good knowledge $(>75 \%)$, average knowledge ( $50-75 \%)$ and poor knowledge $(<50 \%)$ and also, attitude was assessed by likert scale and arbitrarily classified as favorable attitude (>75\%), Neutral attitude (50\%-75\%) and unfavorable attitude $(<50 \%)$. 


\subsection{Pre-testing of tool and Reliability}

Reliability of the instrument was maintained through pre testing of instrument in $10 \%$ of total sample size for arousing the understanding and accuracy of instrument. Pre-testing the instrument was done among $10 \%$ of total sample size at community of Nepalgunj and necessary modification of the instrument was carried out as necessary. Those participants were excluded from the study. Internal consistency and reliability of each set of items for assessment of knowledge and attitude of risk factors was evaluated using Cronbach's alpha test. The reliability coefficients were 0.701 and 0.873 respectively for the scale of knowledge and attitude of risk factors. Thus, the scale was reliable as alpha coefficient in the range 0.70 and above [24].

\section{Operational Definition}

Knowledge: In this study, knowledge refers to the correct responses obtained from general people on risk factors of CVD which will be measured by structured knowledge questionnaire.

Attitude: It refers to the way of thinking, acting and behaving towards risk factors of CVD by respondents as measured by Likert scale.

Risk factors of CVD: It refers to particular habits, behaviors, circumstances or conditions that increase a person's risk of developing CVD.

General people: In this study, general people refers to the people of community with age (20-60) years including both male and female who lives in the community of Dhomboji-1, Nepalgunj.

When the subjects were able to read and write in the national language, they were categorized as literate and vice versa (i.e. illiterate) as defined by the Government of Nepal.

\section{Socio-demographic Characteristics}

Socio-demographic information included age, sex, religion, family income, family type, marital status, education status, occupational status, Present Illness, Eating pattern, Personal habit. Age was collected as a continuous variable and categorized into $20-30,30-40,40-50$, and 50-60 years. Religion was as Hinduism, Muslim, Buddhists, Christianity, Other. Family income was categorized as less than NRs.10,000, 10,000-20,000, 20,000-30000, 30000 and above. Education level was categorized into literate or illiterate. Marital status at the time of data collection was grouped into four groups as married, unmarried, widowed/Widower, Divorced/separated. Occupation was assessed and categorized as government job, business, agriculture. Present illness assessed as hypertension, diabetic mellitus, cancer, asthma, none, eating pattern was Vegetarian, Non- vegetarian and mixed. Personal habit was assessed through smoking, tobacco, Drug, others, none.

\section{Assessment of CVD knowledge}

In the knowledge section, the questionnaire comprised 15 items (i.e. questions or statements) regarding knowledge of CVD risk factors; and each item contained four options. Each of these items (questions) was equally scored. (1 point was given for a correct answer and zero otherwise). These points were then summed 
across all the items. The maximum possible total knowledge score was 15 . Therefore, the total score of this section ranged from 0 to 15 and the higher the score indicated the better the degree of knowledge. Then, the knowledge of CVDs was assessed by total scores of risk factors. Participants who obtained score 12 or more upto 15 (i.e.12-15) points i.e. (>75\%) correct responses having "good knowledge", those with a score between 9 and 11 (i.e. 9-11) points i.e. (50-75\%) were classified as having "average knowledge" while those with a score of 8 points and below i.e. ( $<50 \%)$ were classified as having "poor knowledge" [25]. During analysis and interpretation, participants with good and moderate knowledge were regarded as having "adequate knowledge"

\section{Assessment of CVD Attitude}

In the attitude section, it consisted 20 items and Likert scale was used to assess the level of agreement with the statements on attitude regarding risk factors of CVD among general people. All attitude statements were marked on a 5-points Likert scale such as strongly disagree, disagree, uncertain, agree and strongly agree. Each of these questions was equally scored; response options ranged from 1 (strongly disagree) to 5 (strongly agree). The total score in this section was 20-100 points, and a higher score indicates a more positive attitude. Then, the attitude of CVDs was assessed by total scores of risk factors. Participants who obtained total attitude score between 75 and 100 (75-100) points i.e. (>75\%) were classified as "favourable attitude", those with total attitude score between $50-75$ points i.e. (50-75\%) were classified as having "neutral attitude" and those with total attitude score $<50$ points i.e. $(<50 \%)$ were classified as having "unfavourable attitude" [43].

\section{Statistical Analysis}

The collected data were entered and analysed using IBM-Statistical Package for Social Sciences (SPSS version 21). Descriptive statistical measures such as mean, standard deviation (SD) (i.e. mean SD) for continuous variables and frequencies, percentages were computed for categorical variables. Also, frequency distribution and percentages were performed using frequency tables. Initially, bivariate analysis was performed between the dependent variables (viz. Knowledge and attitude categories) and each of the independent variables (i.e. Socio-demographic variables) to identify important candidate variables for multinomial logistic regression (MNLR) analysis. Chi-square test or Fisher's exact test wherever applicable was used to find the association between two categorical variables; then MNLR model has been used to investigate the significant socio-demographic factors (predictor variables) associated with CVDs knowledge and attitude. We reported odds ratio (OR) with their corresponding 95\% confidence intervals; (AOR, with 95\% C.I.). As the aptness of MNLR model evaluated by Akaike Information Criterion (AIC), Bayesian Information Criterion (BIC), -2log likelihood, likelihood ratio test, goodness of fit, pseudo R-square [42], for the test of model adequacy, -2log likelihood, likelihood ratio test and Pseudo R-square test were applied. For the test of model adequacy, Log likelihood ratio test, and Pseudo R-Square test were applied. Finally, if variables with P-value < 0.05 as a level of significance were considered statistically significant for a two-tailed test otherwise insignificant. Although the dependent variables (knowledge and attitude categories) are ordinal in nature, MNLR model has been used instead of ordinal logistic regression model as the results of test of parallel lines shows the null hypothesis that the slope coefficients in the model are same across the response categories ( $P$ $<0.05$ ), and the model rejected. (The results of test of parallel lines: For knowledge category -2 log Likelihood $=$ 
232.280, chi-square $=41.899, P=0.025<0.05 \&$ for attitude category: -2 log Likelihood $=208.287$, chi-square $=$ 208.287, $P=0.000<0.05)$.

\section{Results}

The findings have been organized and presented under the following sections:

\section{Section A:Description of socio-demographic variables of respondents}

Table 1 shows socio demographic characteristics of general people in which age ranged from 20 to 60 years with a mean SD age of 35.7310 .83 years. Of total 150 respondents, 61(41.7\%) were belonged to age group (20-30) years whereas 22(14.7\%) of them aged between 50-60 years. Regarding sex, more than half of the respondents $82(54.7 \%)$ were female and $68(45.3 \%)$ were male. The majority of the respondents $108(72 \%)$ were literate and $42(28 \%)$ were illiterate. Regarding religion, the most of the respondents $118(78.7 \%)$ were following Hinduism and $8(5.3 \%)$ were Christianity. $78(52 \%)$ of the respondents had government jobs and only $18(12 \%)$ were engaged in agriculture. Furthermore, 80(53.3\%) were married and only 4(2.7\%) were widowed/widower. 78(52.0\%) did not have any present illness whereas only $2(1.3 \%)$ had cancer. Similarly, $56(37.3 \%)$ of the respondents had NRs.30,000 and above family monthly income and 19(12.7\%) had below NRs. 10,000 monthly income. 97(64.7\%) were joint family and 6(4\%) were extended family. The most of the respondents $110(73.3 \%)$ ate mixed food while $40(26.7 \%)$ were vegetarian. The majority of the respondents $101(67.3 \%)$ did not have any personal habit and only 5(3.3 \%) had personal habit of drug abuse.

\section{Section B:Distribution of Knowledge regarding risk factors of CVD among general people}

As shown in the table 2, it reveals that among the total 150 respondents, 35(23.3\%) of respondents had good knowledge, 61(40.7\%) had average knowledge and 54(36\%) had poor knowledge regarding risk factors of CVD (See in figure 1). The overall mean score of respondents on knowledge was $9.28 \pm 2.87$ points. During interpretation, participants with good and moderate knowledge were regarded as having "adequate knowledge". Thus, the results indicate adequate knowledge.

Figure 1 shows that the percentage distribution according to the level of knowledge regarding risk factors of CVD among general people (From section B)

\section{Section C: Distribution of attitude level regarding risk factors of CVD among general people}

The table 3 depicts that majority of the respondents 77(51.3\%) had unfavourable attitude, 54(36\%) had neutral attitude and only 19(12.7\%) had favourable attitude regarding risk factors of CVD9 [43] (See in figure 2). The overall score of respondents with a mean SD of attitude was 52.4912 .98 points.

Figure 2 shows that the percentage distribution according to the level of attitude regarding risk factors of CVD among general people.

\section{Section D: Association between level of Knowledge and Attitude regarding risk factors of CVD with their selected demographic variables.}


The results from the table 4 , since, $p$-value $(P<0.05)$, there were statistically association between level of knowledge and socio-demographic variables such as age $(P=0.023)$, gender $(P=0.038)$, education $(P=$ 0.000), occupation ( $P=0.000)$, monthly family income $(P=0.021)$, marital status $(P=0.023)$, present illness $(P=0.011)$ and remaining other factors ( $P$-value 0.05$)$ such as religion $(P=0.876)$, eating pattern $(P=$ $0.343)$, personal habit $(P=0.411)$ and family type $(P=0.279)$ were not statistically associated with level of knowledge at $5 \%$ level of significance. Considering all these seven statistically associated variables as candidate variables for MNLR through a stepwise selection procedure, then final MNLR analysis came up with two significant predictor variables in association with level of CVD knowledge category namely education and occupation as shown in table 5. Education; illiterates were 80.5\% less likely (AOR = 0.195, 95\% Cl: $0.074-$ $0514, P=0.001<0.05)$ to have average knowledge and $67 \%$ less likely $(A O R=0.330,95 \%$ Cl: $0.117-0.929, P$ $=0.036<0.05$ ) to have good knowledge about risk factors of CVD than literates relative to poor knowledge. Furthermore, occupation; participants having government jobs were 10.389 times more likely $(\mathrm{AOR}=10.389$, $95 \%$ Cl: $2.015-53.560, \mathrm{P}=0.005<0.05)$ to have average knowledge and 12.673 times more likely $(\mathrm{AOR}=$ $12.673,95 \% \mathrm{Cl}: 1.475-108.884, \mathrm{P}=0.021<0.05)$ to have good knowledge as compared to those participants involving agriculture as reference to poor knowledge (Table 5).

From table 6, since, P-value $<0.05$, for selected demographic variables, there were statistically association between level of attitude and socio-demographic variables such as age $(P=0.007)$, gender $(P=0.012)$, education $(P=0.000)$, occupation $(P=0.000)$ and family monthly income $(P=0.036)$ whereas remaining other variables (as p 0.05) such as religion $(P=0.493)$, types of family $(0.693)$, present illness $(P=0.429)$, personal habit $(P=0.433)$, eating pattern $(P=0.438)$, marital status $(P=0.280)$ were not statistically associated with level of attitude at $5 \%$ level of significance. Therefore, these five statistically associated variables as candidate variables for MNLR through a stepwise selection procedure, then final MNLR analysis came up with only two significant predictor variables in association with attitude category namely gender and education as shown in (table 7). Males were $69.9 \%$ less likely ( $\mathrm{AOR}=0.301,95 \% \mathrm{Cl}: 0.140-0.648, \mathrm{P}=0.002<$ $0.05)$ to have unfavourable attitude than female over neutral attitude and illiterates were 4.158 times more likely $(A O R=4.158,95 \% \mathrm{Cl}: 1.707-10.128, p=0.002<0.05)$ to have unfavourable attitude about risk factors of CVD than literates relative to neutral attitude (Table 7 ).

The overall goodness of fit of the estimated model is judged by deviance and Pearson's chi-square. In the Tables 5(i) and 7(i), both Pearson and Deviance residuals are statistically non-significant at $5 \%$ level of significance which suggests that the estimated model fit is well to the MNLR model.

\section{Discussions}

This study assessed the level of knowledge and attitude regarding risk factors of CVD among general people residing in Nepalgunj, Banke; Nepal. This part deals according to the results obtained from the statistical analysis based on the data of the study. The results obtained from this study could help for future strategies and interventions for CVD. In the present study; of total 150 subjects, mean age was 35.7310 .83 years, ranging from 20 to 60 years. The mean scores of respondents for knowledge was $9.28 \pm 2.87$ points. Overall, $35(23.3 \%)$ had good knowledge, 61(40.7\%) had average knowledge and 54(36.0\%) had poor knowledge regarding risk factors of CVD. These findings were in keeping with the results from various studies such as conducted in North- Eastcoast Malaysia in which mean age was of 39.9 years, mean (SD) score for knowledge 
$70.6 \pm 13.7$ and more than half of the respondents $55.6 \%$ had good knowledge [26], another study in Malaysia, with respondents' mean age 39.9 \pm 10.04 years, mean scores for knowledge $36.8 \pm 7.14,55.6 \%$ had good knowledge [27], moderate knowledge with mean score $19.18 \pm 4.46$ in Turkey [28], mean age of participants $42.22 \pm 10.56$ years, mean score for knowledge 31.345 .6 [29], mean score for knowledge 9.0604 .805 scores ranging from 0 to 20 and majority belonged to low level knowledge category (65.20\%) in India [30], moderate knowledge in Kuwait [25], good knowledge with (67\%) in Pakistan [31], median percentage scores for knowledge $79.3 \%$, nearly $44 \%$ of respondents had insufficient knowledge (poor), $36 \%$ had average knowledge and less than $20 \%$ had highly satisfactory knowledge (good) in Nepal [32], the mean scores (SD) for knowledge $60.75 \pm 4.823$, maximum score 71 in Malaysia [33] , mean and standard deviation of the knowledge $42.98 \pm 2.46$ in another study in Malaysia [34], median age (IQR) was $40(33-46)$ years, participant's knowledge of risk factors was low with a mean (SD) score of 1.3 (1.3) out of possible 10 in Kenya [35]. The variations in results might be attributed to differences in study area, scale of classification and categories of enrolled subjects.

In our study, more than half of the respondents $82(54.7 \%)$ were female and $68(45.3 \%)$ of the respondents were male and majority of the respondents $80(53.3 \%)$ were married which were almost consistent results with the study in North western turkey in which nearly half of the respondents $140(46.7 \%)$ were female and majority of the respondents $210(70.0 \%)$ were married [36]. Furthermore, the findings of this study were supported by the previous study in Nepal; median percentage scores for knowledge had 79.3, also, less than $20 \%$ of the respondents had highly satisfactory knowledge (i.e. good knowledge), $36 \%$ of the respondents had average knowledge and nearly half of the respondents $44 \%$ had insufficient knowledge (i.e. poor knowledge) [ 32].

In the present study, overall, $108(72 \%)$ were literate and $42(28 \%)$ illiterate; MNLR analysis revealed that education and profession were significant predictor variables in association with the level of CVD knowledge: Education; illiterates were $80.5 \%$ less likely $(A O R=0.195,95 \% \mathrm{Cl}: 0.074-0.514, \mathrm{P}=0.001<0.05$ ) to have average knowledge and $67 \%$ less likely ( $\mathrm{AOR}=0.330,95 \% \mathrm{Cl}: 0.117-0.929, \mathrm{P}=0.036<0.05)$ to have good knowledge about risk factors of CVD than literates relative to poor knowledge. Furthermore, occupation; participants having government jobs were 10.389 times more likely $(A O R=10.389,95 \% \mathrm{Cl}: 2.015-53.560, \mathrm{P}=$ $0.005<0.05$ ) to have average knowledge and 12.673 times more likely ( $\mathrm{AOR}=12.673,95 \% \mathrm{Cl}: 1.475-$ $108.884, P=0.021<0.05$ ) to have good knowledge as compared to those participants involving agriculture as reference to poor knowledge (Table 5). These findings were almost comparable with the studies conducted in Kenya in which higher education was a strong predictor of CVD risk knowledge (OR $=6.72,95 \%$ Cl: 1.98-22.84, $P<0.0001$ ) [35] in Kuwait, from the multivariate logistic regression analysis, independent predictors of better level of CVD knowledge were females, age 50-59 years, high level of education, regular eating of healthy diet, and had a family history of CVD [25], in Buea Cameroon, from multivariable analysis; high level of education $(\mathrm{AOR}=2.26,95 \% \mathrm{Cl}: 1.69-3.02, \mathrm{P}<0.0001)$, high monthly income $(\mathrm{AOR}=1.64,95 \% \mathrm{Cl}: 1.07-2.51, \mathrm{P}=$ $0.023<0.05)$, having a family history of CVD $(A O R=1.59,95 \% \mathrm{Cl}: 1.21-2.09, \mathrm{P}=0.001<0.05)$ and being a former smoker $(A O R=1.11,95 \% \mathrm{Cl}: 1.02-1.95, P=0.043<0.05)$ were significantly associated with moderateto-good knowledge [37], in Pakistan factors significantly associated with knowledge included age $(P=0.023)$, income $(P<0.001)$, education level $(P<0.001)$, residence $(p<0.001)$, a family history of $C H D(P<0.001)$ and 
a past history of diabetes $(P=0.004)$ [38].This difference could be due to differences between the study populations as gender, occupation, age group, study area.

In this study, majority of the respondents $77(51.3 \%)$ had unfavourable, $54(36 \%)$ had neutral and only $19(12.7 \%)$ had favourable attitude regarding risk factors of CVD. The overall score of respondents with a mean SD of attitude 52.4912 .98 points. This finding was in line with the study done in Jhaukhel - Duwakot, Kathmandu in which median percentage scores for attitude had 74.3 and only $14.7 \%$ had a highly satisfactory attitude and $19.5 \%$ had satisfactory attitude [32] but lower than a study conducted in North-Eastcoast in Malaysian women, which found 55.1\% [26], also lower than other studies in Malaysia, mean (SD) score for attitude $54.36 \pm 8.711$ and $57.12 \pm 5.73[33,34]$, higher than a study conducted in Cuddalore district, India, which found mean (SD) score ( 21.88 1.97) [29], lower than that reported from Lucknow city, India, mean score for attitude $11.82 \pm 5.032,37.6 \%$ score ranging from 0 to 19 [30]. This might be due to variation in study population.

In the present study, more than half of the respondents $82(54.7 \%)$ were female and $68(45.3 \%)$ of were male; 48(32\%) male literates and 60(40\%) female literates. MNLR analysis revealed that gender and education were significant predictor variables in association with level of CVD attitude category. Gender; males were $69.9 \%$ less likely (AOR $=0.301,95 \% \mathrm{Cl}: 0.140-0.648, \mathrm{P}=0.002<0.05$ ) to have unfavourable attitude than female as reference to neutral attitude and education; illiterates were 4.158 times more likely ( $A O R=4.158,95 \% \mathrm{Cl}$ : $1.707-10.128, P=0.002<0.05)$ to have unfavourable attitude about risk factors of CVD than literates relative to neutral attitude (Table 7).

In this study, majority of the respondents $113(75.3 \%)$ answered that the modifiable risk factor of CVD: smoking, physical activity, dietary pattern, high cholesterol, 36(24.0\%) answered non modifiable risk factor of CVD: age, family history, sex, ethnicity and age, smoking, tobacco, stress. These findings were almost consistent with the results $[12,13]$ and almost comparable with previous studies conducted in Lamjung district, Nepal in which smoking $24.1 \%$, harmful use of alcohol $10.7 \%$, insufficient intake of fruit and vegetables $72 \%$, low physical activity $10.1 \%$, overweight and obesity $59.4 \%$, hypertension $42.9 \%$, diabetes $16.2 \%$, dyslipidemia $56.0 \%$ were common risk factors of CVD; and in Kathmandu district, Nepal CVD risk factors included smoking (17.6\%), alcohol consumption (29.4\%), insufficient fruit and vegetables intake (98\%), insufficient physical activity (21.0\%), obesity (15.3\%), hypertension (34.4\%), diabetes (10.5\%) and high triglyceride levels $(10.8 \%)$. The study concluded that the risk factors of CVD was high in rural population of Nepal $[39,40]$, almost consistent with the results of another study in rural Nepalese population, Nepal [39].This difference could be due to the variations between rural and urban populations.

The finding of present study, 133(88.7\%) respondents had known the meaning of CVD as a group of disorder of heart and blood vessel which was supported by the study conducted in Lahore, Pakistan in which 67(60.9\%) answered CVD is related to heart and blood vessels [31].Majority of the respondents $110(73.3 \%)$ answered dizziness, weakness, arm pain sign and symptoms of CVD which was approximately similar to the study conducted in Kuwait, the respondents 728(89.2\%) answered dizziness, weakness, arm pain as sign and symptoms of CVD [25]. More than half of the respondents 88(58.7\%) answered lifestyle modification as treatment of CVD, 100(66.7\%) answered avoid red meat as dietary changes for prevention of CVD. The most of the respondents $121(80.7 \%)$ answered 1 hours and 6(4.0\%) answered 5 hours exercise need to prevent from 
CVD and 100(66.7\%) answered smoking cessation as prevention of CVD which was lower than the study conducted in Italy in which most of the respondents 694(87\%) answered smoking cessation as prevention of CVD in Italy [41].This could be due variation in awareness between study population and probably might be explained by the lack of health education about CVD in the study site.

Regarding attitude in the current study, 21(14\%) participants agreed and 9(6\%) strongly agreed about smoking was the major risk factor of CVD; $11(7.3 \%)$ agreed and 10(6.7\%) strongly agreed about physical activity helps to reduce CVD; $25(16.7 \%)$ agreed and $10(6.7 \%)$ strongly agreed about walking $1 \mathrm{hrs}$ per day can prevent from CVD; $12(8 \%)$ agreed and $12(8 \%)$ strongly agreed about daily intake of enough fruits and vegetables helps to reduce the risks of CVD; $20(13.3 \%)$ agreed and $13(8.7 \%)$ strongly agreed about stress management helps to prevent from CVD; $18(12 \%)$ agreed and $12(8 \%)$ strongly agreed about tobacco chewer have the higher risks of getting CVD; $18(12 \%)$ agreed and $13(8.7 \%)$ strongly agreed about regular medical checkup can prevent from CVD ; $25(16.7 \%)$ agreed and $13(8.7 \%)$ strongly agreed about intake of red meat to increase the risk of CVD. The findings of present study were supported by the study conducted in Lahore, Pakistan with the results quarter of respondents $35(31.8 \%$ ) agreed about walking $1 \mathrm{hrs}$ per day can prevent from CVD. 44(44.5\%) agreed about daily intake of enough fruits and vegetables helps to reduce the risk of CVD, 33(30\%) agreed about stress management helps to prevent from CVD [31], 96\% participants agreed that exercise can prevent CVD, $90 \%$ agreed to prefer walking than taking any other means of transportation, $91 \%$ agreed to eat fruits and vegetables in Kuantan, Malaysia [33].This difference could be due to differences in the study areas and types of participants because our study was not included rural communities.

Our study had some limitations: The study was conducted to selected community of Dhomboji-1, Nepalgunj. The size of the sample was not large enough to make it a representative sample; hence the findings of this study may not be generalized. Despite these limitations, our study had several strengths: This is the first known study to be conducted in mid-western part of Nepal. The present findings would be the first step in providing a quantitative measurement of CVD knowledge and attitude for identifying specific knowledge gaps. This study could aid in the assessment of the adequacy of the present community health educational programs, and could be utilized in designing future targeted public health promotion campaigns to enhance CVD knowledge, improve in attitude and reduce the risk of CVD.

\section{Conclusion And Recommendation}

Based on the above findings and discussions of this study, it is concluded that, even though the attitude was unfavourable but the knowledge was adequate towards risk factors of CVD among general people. For this, health working sectors under government body should make planning and implement of promoting and intervening majors against all risk factors of CVD to reduce its future burden in general people of Nepal from the organizations of various health awareness campaigns. The study recommends to implement the measures such as NTCP, DURRP, DMP, MMMP formulated by ministry of health and population, Nepal in order to reduce risk factors of CVD locally and globally.

\section{Abbreviations}


CVDs: Cardiovascular diseases; CVD: Cardiovascular disease, NCD: Non-communicable disease; CHD: coronary heart disease; THI: Texas Heart Institute; WHO: World Health Organization, Cl: Confidence interval, COR: Crude odds ratio, AOR: Adjusted odds ratio, MNLR: Multinomial logistic regression; NTCP: National tobacco control Programme; DMP: Disease management programme; DURRP: Drug use risk reduction programme; MMMP: May measurement month Programme.

\section{Declarations}

\section{Ethics approval and consent to participate}

Data in this study has been performed in accordance with the guidelines of the authority of ward office no. 1, Dhamboji of Nepalgunj, sub-metropolitan city, Banke; Nepal. The health sector of this area is under the supervision of ward authority. The approval is issued in the letter head of the office including reference number 2076/77 B.S., 546. As per the guidelines of the authority, privacy and confidentiality of the respondents have been maintained. A written informed consent was obtained from most of the participants and some of them provided only verbal consent as they were illiterate. The purpose and objectives of the study were explained to each participant prior to interview and then data were collected as guided by the ethical committee of ward office. Participants were voluntary.

\section{Consent to publish}

Not applicable

\section{Availability of data and materials}

The required data and materials are available at the hands for this study from designing structured questionnaire and face to face interview. Proper precaution has been taken to maintain privacy and confidentiality of the data. The co-author has been commissioned to collect data.

\section{Competing interests}

The authors declare that they have no competing interests.

\section{Funding}

No funding has been received in conducting this research.

\section{Authors' Contributions}

To complete this study, RPT has contributed in designing, supervising, analysing data and writing the manuscript. SR has done in developing and pre-testing of the questionnaire, collecting data, reviewing the manuscript and interpreting the results. Both authors read and approved the final manuscript.

\section{Acknowledgements}

We are thankful to all the participants of study for their cooperation. 


\section{Authors' details}

${ }^{1}$ Lecturer, Tribhuvan University, Kathamandu, Department of Statistics, Mahendra Multiple Campus, Nepalgunj, Banke; Nepal

${ }^{2}$ Department of Nursing, Bheri Nursing College, Nepalgunj, Banke; Affiliated to Purbanchal University, Nepal

\section{References}

1. WHO. Cardiovascular diseases (CVDs). 17 May 2017 [Internet]. Available from URL: https://www.who.int/news-room/fact-sheets/detail/cardiovascular-diseases-(cvds)

2. Coronary Heart Disease in Nepal -World Life Expectancy; Health Profile, Nepal. Available from: https://www.worldlifeexpectancy.com/country-health-profile/nepal

3. World Health Organization: Cardiovascular diseases (CVDs): Fact sheet No. 317. http://www.who.int/mediacentre/factsheets/fs317/en/.

4. Benjamin EJ, Muntner P, Bittencourt MS. Heart disease and stroke statistics-2019 update: a report from the American Heart Association. Circulation. 2019; 139(10):e56-28.

5. Ueshima H, Sekikawa A, Miura K, Turin TC, Takashima N, Kita Y, et al. Cardiovascular disease and risk factors in Asia: a selected review. Circulation.2008; 118(25):2702-2709.

6. Reddy KKR, Rao AP, Reddy TPK. Socioeconomic status and the prevalence of coronary heart disease risk factors. Asia Pacific Journal of Clinical Nutrition. 2002; 11(2): 98-103. https://doi.org/10.1046/j.14406047.2002.00267.x PMid: 12074188

7. Limbu Y R, Maskey A, K.C. Man Bahadur, Malla R, Sharma D, Shrestha N K. A study on cardiovascular disease pattern of admitted cases in newly emerged national heart centre. J Nepal Med Assoc. 2001:41:284-8.

8. Shankar PR, Partha P, Shenoy N, Chandrasekhar TS, Dubey AK. Knowledge about heart attack and hypertension among individuals attending a cardiac camp in Pokhara city. K U Med J; 5(2): 273-278. Available from: http://www.ncbi.nlm.nih.gov/pubmed/18604037.

9. WHO. Global Atlas on Cardiovascular Diseases Prevention Control. Geneva: WHO; 2011.

10. Pyakurel P, Karki P, Lamsal M, Ghimire A, Pokharel PK. Cardiovascular risk factors among industrial workers: a cross-sectional study from eastern Nepal. J Occup Med Toxicol. 2016; 11:25.

11. Department of Health Services, Ministry of Health and Population, Government of Nepal. Annual Report [Internet].2074/75(2017/18):217. Available from: https://dohs.gov.np/wpcontent/uploads/2019/07/DoHS-Annual-Report-FY-2074-75-date-22-Ashad-2076-for-web-.1 pdf

12. Anderson KM, Odell PM, Wilson PW, Kannel WB. Cardiovascular disease risk profiles. American heart journal. 1991 Jan 1; 121(1):293-8.

13. World Health Organization. Global health risks: mortality and burden of disease attributable to selected major risks. Geneva: World Health Organization; 2009.

14. Glassman AH, Helzer JE, Covey LS, Cottler LB, Stetner F, Tipp JE, Johnson J. Smoking, smoking cessation, and major depression. Jama.1990 Sep 26; 264(12):1546-9. 
15. World Health Organization. Global Health Risks: Mortality and Burden of Disease Attributable to Selected Major Risks. World Health Organization; 2009

16. Mendis S, Puska P, Norrving B: Global Atlas on Cardiovascular Disease Prevention and Control. Geneva, Switzerland: World Health Organization; 2011.

17. World Health Organization, Nepal Health Research Council: Non Communicable Diseases Risk Factor, STEPS Survey 2013 Nepal, Fact Sheet; 2013

18. Alwan A. Global Status Report on Non-communicable Diseases 2010. Geneva, Switzerland: World Health Organization; 2011.

19. Kearney PM, Whelton M, Reynolds K, Muntner P, Whelton PK, He J. Global burden of hypertension: analysis of worldwide data. The lancet. 2005 Jan 15; 365(9455):217-23

20. Marks JB, Raskin P. Cardiovascular risk in diabetes: a brief review. Journal of Diabetes and its Complications. 2000 Mar 1; 14(2):108-15

21. Aryal KK, Mehata S, Neupane S, Vaidya A, Dhimal M, Dhakal P, Rana S, Bhusal CL, Lohani GR, Paulin FH, et al. The burden and determinants of non-communicable diseases risk factors in Nepal: findings from a Nationwide STEPS survey. PLoS One. 2015; 10(8):e0134834.

22. Khanal MK, Dhungana RR, Bhandari P, Gurung Y, Paudel KN. Prevalence, associated factors, awareness, treatment, and control of hypertension: Findings from a cross sectional study conducted as a part of a community based intervention trial in Surkhet, Mid-western region of Nepal. PLoS One. 2017:12(10): e0185806. https://doi.org/10.1371/journal.

23. Vaidya A. Tackling cardiovascular health and disease in Nepal: epidemiology, strategies and implementation. Heart Asia 2011; 3(1): 87-91.

24. Robinson JP, Shaver PR, Wrightsman LS. Criteria for Scale Selection and Evaluation. In: Measures of Personality and Social Psychological Attitudes. 1991.

25. Awad A, Al-Nafisi H. Public knowledge of cardiovascular disease and its risk factors in Kuwait: a crosssectional survey. BMC Public Health. 2014 Nov4; 14:1131

26. Muhamad R, Yahya R, Yusoff HM. Knowledge, attitude and practice on cardiovascular disease among women in North-Eastcoast Malaysia. . International Journal of Collaborative Research on Internal Medicine \& Public Health. 2012 Jan; 4(1):85-98

27. Yahya R, Muhamad R, Yusoff HM. Association between Knowledge, Attitude and Practice on Cardiovascular Disease among Women in Kelantan, Malaysia. International Journal of Collaborative Research on Internal Medicine \& Public Health. Vol. 4 No. 8 (2012)

28. Andsoy,I.I., Taştan, S., lyigun, E., \& Kopp, L.R. Knowledge and Attitudes towards cardiovascular Disease in a Population of North Western Turkey: A Cross- Sectional Survey. International Journal of Caring Sciences $2015: 8(1): 115$

29. Muthukrishnan G, Kingston C, Ravikumar A. A cross sectional study of knowledge, attitude and practice on cardiovascular disease and its risk factors among anganwadi workers of Cuddalore district. Int. J Community Med Public Health 2018; 5:2406-10.

30. Dayal B and Singh N. Association between knowledge, attitude and practice on cardiovascular disease among early adults of Lucknow city. Al Ameen J Med Sci 2018; 11(1):59-65. 
31. S. Ejaz et al. Knowledge, Attitude and Practice Regarding Modifiable Risk Factors of Cardiovascular Diseases among Adults in Rural Community, Lahore. Int. J. Soc. Sc. Manage. 2018;5(3): 76-82

32. Vaidya A, Aryal UR, Krettek A. Cardiovascular health knowledge, attitude and practice/behaviour in an urbanising community of Nepal: a population-based cross-sectional study from Jhaukhel-Duwakot Health Demographic Surveillance Site. BMJ open. 2013 Oct 2; 3(10):e002976.

33. Mohammad NB, Rahman NA, Haque M. Knowledge, attitude, and practice regarding the risk of cardiovascular diseases in patients attending outpatient clinic in Kuantan, Malaysia.J Pharm Bioall Sci 2018;10:7-14.

34. Ibrahim MM, Rahman NAA, Rahman NIA, Haque M. Knowledge, Attitude and Practice of Malaysian Public University Students on Risk Factors for Cardiovascular Diseases. J App Pharm Sci, 2016; 6 (02): 056-063.

35. Temu, T. M., Kirui, N., Wanjalla, C., Ndungu, A. M., Kamano, J. H., Inui, T. S., \& Bloomfield, G. S. Cardiovascular health knowledge and preventive practices in people living with HIV in Kenya. BMC infectious diseases, 2015; 15, 421.

36. Kopp L.R. Knowledge and attitudes towards cardiovascular disease in a population of North Western Turkey: A cross-sectional survey. International Journal of Caring Sciences. 2015;8(1):115.

37. Aminde LN, Takah N, Ngwasiri C, Noubiap JJ , Tindong M, Dzudie A and Veerman J.L. Population awareness of cardiovascular disease and its risk factors in Buea, Cameroon. BMC Public Health. 2017, 17:545

38. Jafary FH, Aslam F, Mahmud H, Waheed A, Shakir M, Afzal A, Qayyum MA, Akram J, Khan IS, Haque IU: Cardiovascular health knowledge and behavior in patient attendants at four tertiary care hospitals in Pakistan- a cause for concern. BMC Public Health 2005, 5:124.

39. Khanal MK, Ahmed MM, Moniruzzaman M, Banik PC, Dhungana RR, Bhandari P, Devkota S, Shayami A. Prevalence and clustering of cardiovascular disease risk factors in rural Nepalese population aged $40-80$ years. BMC public health. 2018 Dec; 18(1):677.

40. Dhungana RR, Thapa P, Devkota S, Banik PC, Gurung Y, Mumu SJ, Shayami A, Ali L. Prevalence of cardiovascular disease risk factors: A community-based cross-sectional study in a peri-urban community of Kathmandu, Nepal. Indian heart journal. 2018 Dec 1; 70:S20-S27.

41. Tedesco LM, Di Giuseppe G, Napolitano F, Angelillo IF. Cardiovascular diseases and women: knowledge, attitudes, and behavior in the general population in Italy. BioMed research international. 2015; 201

42. A. Field, Discovering Statistics Using IBM SPSS Statistics. SAGE, 2013; $4^{\text {th }}$ edition.

43. Verma A, Mehta S, Mehta A, Patyal A. Knowledge, attitude and practices toward health behavior and cardiovascular disease risk factors among the patients of metabolic syndrome in a teaching hospital in India. J Family Med Prim Care. 2019 Jan; 8(1):178-183.

\section{Tables}

Table 1: Frequency and Percentage distribution of respondents according to selected Socio- Demographic Variables (This table belongs to results of Section A) $\quad n=150$ 


\begin{tabular}{|c|c|c|c|}
\hline \multirow{2}{*}{$\begin{array}{l}\text { S.No. } \\
1\end{array}$} & \multicolumn{2}{|c|}{ Socio-Demographic variables } & \multirow{2}{*}{$\begin{array}{l}\text { Frequency (\%) } \\
61(40.7)\end{array}$} \\
\hline & Age & $20-30$ & \\
\hline & & $30-40$ & $39(26.0)$ \\
\hline & & $40-50$ & 28(18.7) \\
\hline & & $50-60$ & $22(14.7)$ \\
\hline & & Mean SD & 35.7310 .83 \\
\hline \multirow[t]{2}{*}{2} & Sex & Male & $68(45.3)$ \\
\hline & & Female & $82(54.7)$ \\
\hline \multirow[t]{2}{*}{3} & Educational status & Literate & 108(72.0) \\
\hline & & Illiterate & $42(28.0)$ \\
\hline \multirow[t]{4}{*}{4} & Religion & Hinduism & 118(78.7) \\
\hline & & Islam & $15(10.0)$ \\
\hline & & Buddhism & $9(6.0)$ \\
\hline & & Christianity & $8(5.3)$ \\
\hline \multirow[t]{3}{*}{5} & Occupation & Government job & $78(52.0)$ \\
\hline & & Business & $54(36.0)$ \\
\hline & & Agriculture & $18(12.0)$ \\
\hline \multirow[t]{4}{*}{6} & Marital status & Married & $80(53.3)$ \\
\hline & & Unmarried & $59(39.3)$ \\
\hline & & Widowed/ Widower & $4(2.7)$ \\
\hline & & Divorced & $7(4.7)$ \\
\hline \multirow[t]{5}{*}{7} & Present illness & Hypertension & $16(10.7)$ \\
\hline & & Diabetic mellitus & $50(33.3)$ \\
\hline & & Cancer & $2(1.3)$ \\
\hline & & Asthma & $4(2.7)$ \\
\hline & & None & $78(52.0)$ \\
\hline \multirow[t]{4}{*}{8} & Family monthly income & Below NRs. 10,000 & 19(12.7) \\
\hline & & NRs. $10,000-20,000$ & $31(20.7)$ \\
\hline & & NRs.20,000-30,000 & $44(29.3)$ \\
\hline & & NRs.30,000 and above & $56(37.3)$ \\
\hline 9 & Types of family & Nuclear & $47(31.3)$ \\
\hline
\end{tabular}




\begin{tabular}{|llll|} 
& & Joint & $97(64.7)$ \\
& & Extended & $6(4.0)$ \\
& \multirow{2}{*}{ Eating pattern } & Vegetarian & $40(26.7)$ \\
& & Non-vegetarian & - \\
& & Mixed & $110(73.3)$ \\
\hline 11 & Personal habit & Smoking & $28(18.7)$ \\
& & Tobacco & $16(10.7)$ \\
& & Drug abuse & $5(3.3)$ \\
& & None & $101(67.3)$ \\
\hline
\end{tabular}

Table 2: Frequency and Percentage Distribution of Level of Knowledge to assess the risk factor of CVD among general people. $n=150$

\begin{tabular}{|llll|}
\hline S.No. & Level of Knowledge & Range of score & Frequency (\%) \\
\hline 1 & Good knowledge & $12-15(>75 \%)$ & $35(23.3 \%)$ \\
\hline 3 & Average knowledge & $9-11(50 \%-75 \%)$ & $61(40.7 \%)$ \\
\hline
\end{tabular}

Minimum score $=0$

Maximum score $=15$

Table 3: Frequency and Percentage Distribution of level of attitude to assess the risk factors of CVD among general people. $\quad n=150$

Likert scale to assess risk factor of cardio vascular disease among general people.

\begin{tabular}{|llcl|}
\hline S.No. & Attitude level & Range of score & Frequency (\%) \\
\hline 1 & Favourable & $75-100(>75 \%)$ & $19(12.7 \%)$ \\
\hline 2 & Neutral & $50-75(50 \%-75 \%)$ & $54(36.0 \%)$ \\
\hline 3 & Unfavourable & $<50(<50 \%)$ & $77(51.3 \%)$ \\
\hline Minimum score $=20$ & & Maximum score $=100$ \\
\hline
\end{tabular}


Table 4: Association between level of Knowledge regarding risk factors of CVD with their selected demographic variables [43] (This table belongs to result: section D) 


\begin{tabular}{|c|c|c|c|c|c|c|c|}
\hline \multirow[t]{3}{*}{ S.No. } & \multicolumn{2}{|c|}{ Socio-demographic variables } & \multicolumn{3}{|c|}{ Level of knowledge } & \multirow{3}{*}{$\begin{array}{l}\text { Chi- } \\
\text { square }\end{array}$} & \multirow[t]{3}{*}{ P-value } \\
\hline & & & Good & Average & Poor & & \\
\hline & & & $n(\%)$ & $\begin{array}{c}n \\
(\%)\end{array}$ & n (\%) & & \\
\hline \multirow[t]{4}{*}{1} & \multirow[t]{4}{*}{ Age } & $20-30$ & $13(8.67)$ & $30(20)$ & $18(12)$ & & \\
\hline & & $30-40$ & 11(7.33) & 14(9.33) & $14(9.33)$ & 14.629 & $0.023^{*}$ \\
\hline & & $40-50$ & $7(4.67)$ & 14(9.33) & $7(4.67)$ & & \\
\hline & & $50-60$ & $4(2.67)$ & $3(2)$ & $15(10)$ & & \\
\hline \multirow[t]{3}{*}{2} & \multirow[t]{3}{*}{ Sex } & Male & \multirow{2}{*}{$\begin{array}{l}19 \\
(12.67)\end{array}$} & \multirow{2}{*}{$\begin{array}{l}32 \\
(21.33)\end{array}$} & 17(11.33) & & \\
\hline & & Female & & & $37(24.67)$ & \multirow{2}{*}{6.563} & \multirow{2}{*}{$0.038^{*}$} \\
\hline & & & 16(10.67) & $\begin{array}{l}29 \\
(19.33)\end{array}$ & & & \\
\hline \multirow[t]{2}{*}{3} & \multirow{2}{*}{$\begin{array}{l}\text { Educational } \\
\text { status }\end{array}$} & Literate & $28(18.67)$ & $53(35.33)$ & $27(18)$ & & \\
\hline & & Illiterate & $7(4.67)$ & $8(5.33)$ & $27(18)$ & 20.780 & $0.000 *$ \\
\hline \multirow[t]{4}{*}{4} & \multirow[t]{4}{*}{ Religion } & Hinduism & $27(18)$ & $51(34)$ & $40(26.67)$ & & \\
\hline & & Islam & $4(2.67)$ & $5(3.33)$ & $6(4)$ & \multirow[t]{3}{*}{2.429} & \multirow[t]{3}{*}{$0.876^{\star *}$} \\
\hline & & Buddhism & $2(1.33)$ & $2(1.33)$ & $5(3.33)$ & & \\
\hline & & Christianity & $2(1.33)$ & $3(2)$ & $3(2)$ & & \\
\hline \multirow[t]{3}{*}{5} & \multirow[t]{3}{*}{ Occupation } & Government job & $21(14)$ & $39(26)$ & 18(12) & & \\
\hline & & Business & $13(8.67)$ & \multirow{2}{*}{$\begin{array}{l}20 \\
(13.33)\end{array}$} & $21(14)$ & \multirow[t]{2}{*}{23.540} & \multirow[t]{2}{*}{$0.000 *$} \\
\hline & & Agriculture & $1(0.67)$ & & 15(10) & & \\
\hline \multirow[t]{5}{*}{6} & \multirow{5}{*}{$\begin{array}{l}\text { Present } \\
\text { Illness }\end{array}$} & Hypertension & $0(0.00)$ & $5(3.33)$ & 11(7.33) & & \\
\hline & & Diabetic & $16(10.67)$ & $22(14.67)$ & $12(8)$ & \multirow[t]{4}{*}{19.792} & \multirow[t]{4}{*}{$0.011^{*}$} \\
\hline & & Cancer & $0(0.00)$ & $0(0.00)$ & $2(1.33)$ & & \\
\hline & & Asthma & $1(0.67)$ & $0(0.00)$ & $3(2)$ & & \\
\hline & & None & 18(12) & $34(22.67)$ & $26(17.33)$ & & \\
\hline \multirow[t]{3}{*}{7} & \multirow{3}{*}{$\begin{array}{l}\text { Eating } \\
\text { pattern }\end{array}$} & Vegetarian & $9(6)$ & $13(8.67)$ & $18(12)$ & & \\
\hline & & Non-vegetarian & - & - & - & \multirow[t]{2}{*}{2.138} & $0.343^{\star *}$ \\
\hline & & Mixed & $26(17.33)$ & $48(32)$ & $36(24)$ & & \\
\hline 8 & Personal & Smoking & $5(3.33)$ & $12(8)$ & 11(7.33) & & \\
\hline & & Tobacco & $7(4.67)$ & $4(2.67)$ & $5(3.33)$ & 6.114 & 0.411 ** \\
\hline
\end{tabular}




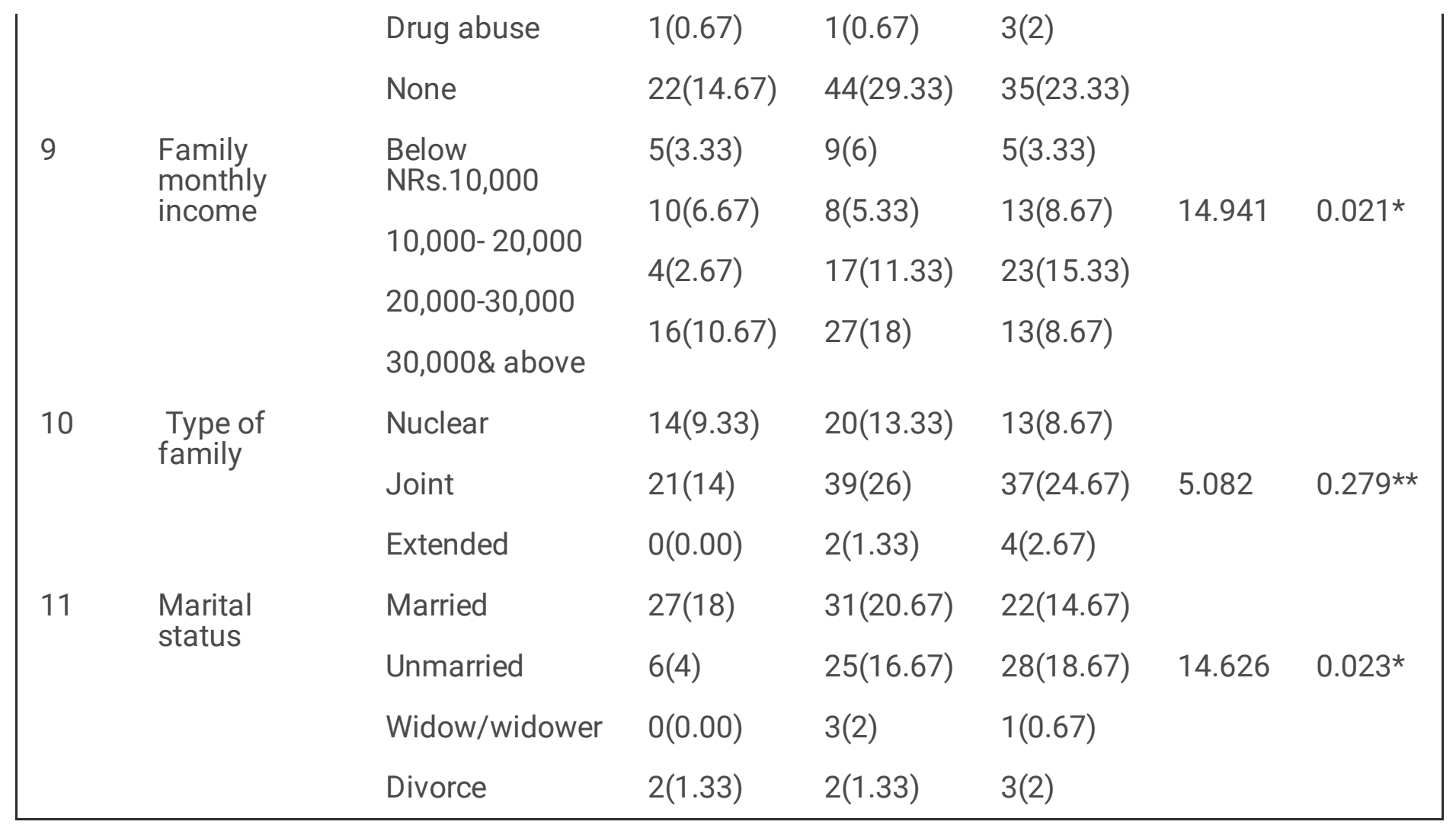

*Significant, ** Non-Significant: Significant ( $p$-value < 0.05) \& Not significant ( $p$-value 0.05) for two tailed test at $5 \%(0.05)$ level of significance.

Table 5 : Significant predictor variables in association with level of CVD knowledge category in MNLR Model: 


\begin{tabular}{|c|c|c|c|c|c|c|}
\hline $\begin{array}{l}\text { Knowledge } \\
\text { category }\end{array}$ & Variables & Category & B & $\begin{array}{l}\mathrm{P} \text { - } \\
\text { value }\end{array}$ & AOR $(95 \% \mathrm{Cl})$ & $\operatorname{COR}(95 \% \mathrm{Cl})$ \\
\hline \multirow{6}{*}{$\begin{array}{l}\text { Average } \\
\text { Knowledge }\end{array}$} & Intercept & & -1.141 & 0.155 & - & - \\
\hline & \multirow[t]{2}{*}{ Education } & Illiterate & -1.634 & 0.001 & $\begin{array}{l}0.195(0.074- \\
0.514)\end{array}$ & $\begin{array}{l}0.151(0.60- \\
0.377)\end{array}$ \\
\hline & & Literate & & \multicolumn{2}{|c|}{ Reference } & \\
\hline & \multirow[t]{3}{*}{ Occupation } & $\begin{array}{l}\text { Government } \\
\text { job }\end{array}$ & 2.341 & 0.005 & $\begin{array}{l}10.389(2.015- \\
53.560)\end{array}$ & $\begin{array}{l}\text { 16.25(3.355- } \\
78.702)\end{array}$ \\
\hline & & Business & 1.479 & 0.082 & $\begin{array}{l}4.390(0.829- \\
23.235)\end{array}$ & $\begin{array}{l}7.143(1.446- \\
35.288)\end{array}$ \\
\hline & & Agriculture & & \multicolumn{2}{|c|}{ Reference } & \\
\hline \multirow{6}{*}{$\begin{array}{l}\text { Good } \\
\text { knowledge }\end{array}$} & Intercept & & -2.044 & 0.057 & - & - \\
\hline & \multirow[t]{2}{*}{ Education } & Illiterate & -1.109 & 0.036 & $\begin{array}{l}0.330(0.117- \\
0.929)\end{array}$ & $\begin{array}{l}0.250(0.093- \\
0.670)\end{array}$ \\
\hline & & Literate & & \multicolumn{2}{|c|}{ Reference } & \\
\hline & \multirow[t]{3}{*}{ Occupation } & $\begin{array}{l}\text { Government } \\
\text { job }\end{array}$ & 2.540 & 0.021 & $\begin{array}{l}12.673(1.475- \\
108.88)\end{array}$ & $\begin{array}{l}17.50(2.101- \\
145.778)\end{array}$ \\
\hline & & Business & 1.875 & 0.091 & $\begin{array}{l}6.524(0.741- \\
57.462)\end{array}$ & $\begin{array}{l}9.286(1.093- \\
78.857)\end{array}$ \\
\hline & & Agriculture & & \multicolumn{2}{|c|}{ Reference } & \\
\hline
\end{tabular}

The reference category is: Poor knowledge

Model Fitting information : Ch-square $=35.898 ; P=0.000<0.0001,-2$ Log Likelihood $=36.044$, Pseudo Rsqure: $($ Cox and Snell $=0.213$, Nagelkerke $=0.241$, McFadden $=0.111)$

Table 5 (i): Test of the Goodness of Fit

\begin{tabular}{|llll|}
\hline & Chi-Square & d.f. & P-value \\
\hline Pearson & 3.401 & 4 & 0.493 \\
\hline Deviance & 3.938 & 4 & 0.414 \\
\hline
\end{tabular}

Table 6: Association between level of Attitude regarding risk factors of CVD with their selected demographic variables 


\begin{tabular}{|c|c|c|c|c|c|c|c|}
\hline \multirow[t]{3}{*}{ S.No. } & \multicolumn{2}{|c|}{ Socio-demographic variables } & \multicolumn{2}{|c|}{ Level of Attitude } & \multirow{3}{*}{$\begin{array}{l}\text { Favourable } \\
\text { n (\%) }\end{array}$} & \multirow{3}{*}{$\begin{array}{l}\text { Chi- } \\
\text { square }\end{array}$} & \multirow[t]{3}{*}{ P-value } \\
\hline & & & Unfavourable & Neutral & & & \\
\hline & & & $n(\%)$ & $\mathrm{n}(\%)$ & & & \\
\hline & Age & $20-30$ & $30(20)$ & $24(16)$ & $7(4.67)$ & & \\
\hline & & $30-40$ & 16(10.67) & 16(10.67) & $7(4.67)$ & 17.853 & $0.007^{\star}$ \\
\hline & & $40-50$ & $11(7.33)$ & $13(8.67)$ & $4(2.67)$ & & \\
\hline & & $50-60$ & 20(13.33) & $1(0.67)$ & $1(0.67)$ & & \\
\hline \multirow[t]{2}{*}{2} & Sex & Male & 26(17.33) & 32(21.33) & $10(6.67)$ & & \\
\hline & & Female & $51(34)$ & $22(14.67)$ & $9(6)$ & 8.791 & $0.012^{\star}$ \\
\hline \multirow[t]{2}{*}{3} & \multirow{2}{*}{$\begin{array}{l}\text { Educational } \\
\text { status }\end{array}$} & Literate & $45(30)$ & $45(30)$ & 18(12) & & \\
\hline & & Illiterate & $32(21.33)$ & $9(6)$ & $1(0.67)$ & 15.334 & $0.000 *$ \\
\hline \multirow[t]{4}{*}{4} & \multirow[t]{4}{*}{ Religion } & Hinduism & $61(40.67)$ & $44(29.33)$ & 13(8.67) & 5.404 & $0.493^{\star *}$ \\
\hline & & Islam(Muslim) & 6(4) & $5(3.33)$ & $4(2.67)$ & & \\
\hline & & Buddhism & $5(3.33)$ & $2(1.33)$ & $2(1.33)$ & & \\
\hline & & Christianity & $5(3.33)$ & $3(2)$ & $0(0.00)$ & & \\
\hline \multirow[t]{3}{*}{5} & \multirow[t]{3}{*}{ Occupation } & Government job & $33(22)$ & $34(22.67)$ & $11(7.33)$ & & \\
\hline & & Business & 26(17.33) & 20(13.33) & $8(5.33)$ & 19.997 & $0.000 *$ \\
\hline & & Agriculture & 18(12) & $0(0.00)$ & $0(0.00)$ & & \\
\hline \multirow[t]{4}{*}{6} & \multirow{4}{*}{$\begin{array}{l}\text { Family } \\
\text { income }\end{array}$} & Below 10,000 & $8(5.33)$ & $9(6)$ & $2(1.33)$ & & \\
\hline & & $10,000-20000$ & 17(11.33) & $6(4)$ & $8(5.33)$ & 13.501 & $0.036^{\star}$ \\
\hline & & $20,000-30,000$ & $28(18.67)$ & 14(9.33) & $2(1.33)$ & & \\
\hline & & $30,000 \&$ above & $24(16)$ & 25(16.67) & $7(4.67)$ & & \\
\hline \multirow[t]{3}{*}{7} & \multirow{3}{*}{$\begin{array}{l}\text { Types of } \\
\text { family }\end{array}$} & Nuclear & $27(18)$ & $15(10)$ & $5(3.33)$ & & \\
\hline & & Joint & 47(31.33) & $36(24)$ & 14(9.33) & 2.230 & $0.693^{* *}$ \\
\hline & & Extended & $3(2)$ & $3(2)$ & $0(0.00)$ & & \\
\hline \multirow[t]{4}{*}{8} & \multirow{4}{*}{$\begin{array}{l}\text { Marital } \\
\text { status }\end{array}$} & Married & $36(24)$ & 29(19.33) & $15(10)$ & 7.471 & $0.280 * *$ \\
\hline & & Unmarried & $33(22)$ & $22(14.67)$ & $4(2.67)$ & & \\
\hline & & Widow/widower & $3(2)$ & $1(0.67)$ & $0(0.00)$ & & \\
\hline & & Divorce & $5(3.33)$ & $2(1.33)$ & $0(0.00)$ & & \\
\hline \multirow[t]{2}{*}{9} & \multirow{2}{*}{$\begin{array}{l}\text { Present } \\
\text { illness }\end{array}$} & Hypertension & 11(7.33) & $5(3.33)$ & $0(0.00)$ & 8.048 & $0.429 * *$ \\
\hline & & Diabetic & $24(16)$ & 19(12.67) & $7(4.67)$ & & \\
\hline
\end{tabular}




\begin{tabular}{|c|c|c|c|c|c|c|c|}
\hline & & \multirow{2}{*}{$\begin{array}{l}\text { Cancer } \\
\text { Asthma }\end{array}$} & $2(1.33)$ & $0(0.00)$ & \multicolumn{3}{|l|}{$0(0.00)$} \\
\hline & & & $3(2)$ & $0(0.00)$ & $1((0.67)$ & & \\
\hline & & None & $37(24.67)$ & $30(20)$ & 11(7.33) & & \\
\hline \multirow[t]{3}{*}{10} & \multirow{3}{*}{$\begin{array}{l}\text { Eating } \\
\text { pattern }\end{array}$} & Vegetarian & $24(16)$ & $12(8)$ & $4(2.67)$ & 1.650 & $0.438^{\star \star}$ \\
\hline & & Non-vegetarian & - & - & - & & \\
\hline & & Mixed & $53(35.33)$ & $42(28)$ & $15(10)$ & & \\
\hline \multirow[t]{4}{*}{11} & \multirow{4}{*}{$\begin{array}{l}\text { Personal } \\
\text { habit }\end{array}$} & Smoking & 13(8.67) & $13(8.67)$ & $2(1.33)$ & 5.913 & $0.433^{\star \star}$ \\
\hline & & Tobacco & $8(5.33)$ & $4(2.67)$ & $4(2.67)$ & & \\
\hline & & Drug abuse & $4(2.67)$ & $1(0.67)$ & $0(0.00)$ & & \\
\hline & & None & $52(34.67)$ & $36(24)$ & $13(8.67)$ & & \\
\hline
\end{tabular}

*Significant, ** Non-Significant: Significant ( $p$-value $\leq 0.05)$ \& Not significant ( $p$-value $>0.05$ ) for two tailed test at $5 \%(0.05)$ level of significance.

Table 7: Significant predictor variables in association with level of CVD attitude category in MNLR Model:

\begin{tabular}{|c|c|c|c|c|c|c|}
\hline Attitude category & Variables & Category & B & $\begin{array}{l}\mathrm{P} \text { - } \\
\text { value }\end{array}$ & $\operatorname{AOR}(95 \% \mathrm{Cl})$ & $\operatorname{coR}(95 \% \mathrm{Cl})$ \\
\hline \multirow{5}{*}{$\begin{array}{l}\text { Unfavourable } \\
\text { Attitude }\end{array}$} & Intercept & & 0.510 & 0.063 & - & - \\
\hline & \multirow[t]{2}{*}{ Gender } & Male & -1.199 & 0.002 & $\begin{array}{l}0.301(0.140- \\
0.648)\end{array}$ & $0.35(0.171-0.72)$ \\
\hline & & Female & & \multicolumn{2}{|c|}{ Reference } & \\
\hline & \multirow[t]{2}{*}{ Education } & Illiterate & 1.425 & 0.002 & $\begin{array}{l}4.158(1.707- \\
10.128)\end{array}$ & $\begin{array}{l}3.556(1.524- \\
8.295)\end{array}$ \\
\hline & & Literate & & \multicolumn{2}{|c|}{ Reference } & \\
\hline \multirow{5}{*}{ Favourable Attitude } & Intercept & & $\overline{0} .801$ & 0.046 & - & - \\
\hline & \multirow[t]{2}{*}{ Gender } & Male & -0.211 & 0.695 & $\begin{array}{l}0.809(0.281- \\
2.329)\end{array}$ & $\begin{array}{l}0.764(0.267- \\
2.186)\end{array}$ \\
\hline & & Female & & \multicolumn{2}{|c|}{ Reference } & \\
\hline & \multirow[t]{2}{*}{ Education } & Illiterate & -1.254 & 0.251 & $\begin{array}{l}0.285(0.034- \\
2.429)\end{array}$ & $\begin{array}{l}0.278(0.033- \\
2.354)\end{array}$ \\
\hline & & Literate & & \multicolumn{2}{|c|}{ Reference } & \\
\hline
\end{tabular}

The reference category is: Neutral Attitude 
Model Fitting information : Ch-square $=27.395 ; \mathrm{P}=0.000<0.0001,-2$ Log Likelihood $=25.467$, Pseudo Rsqure: $($ Cox and Snell $=0.167$, Nagelkerke $=0.195$, McFadden $=0.094)$

Table 7 (i): Test of the Goodness of Fit

\begin{tabular}{|llll|}
\hline & Chi-Square & d.f. & P-value \\
\hline Pearson & 1.175 & 2 & 0.556 \\
\hline Deviance & 1.515 & 2 & 0.469 \\
\hline
\end{tabular}

Figures

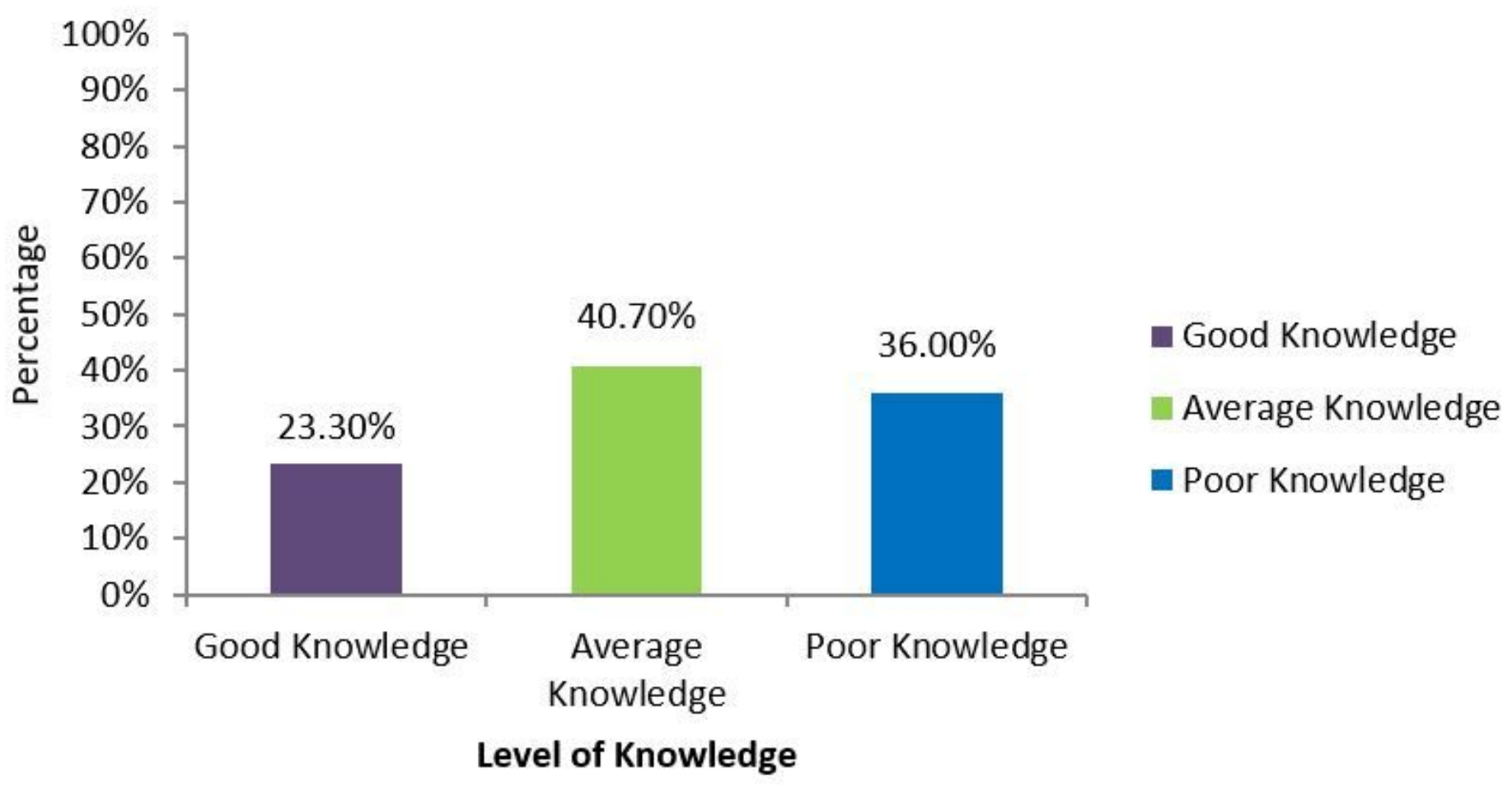

Figure 1

Level of knowledge regarding risk factors of CVD among general people 


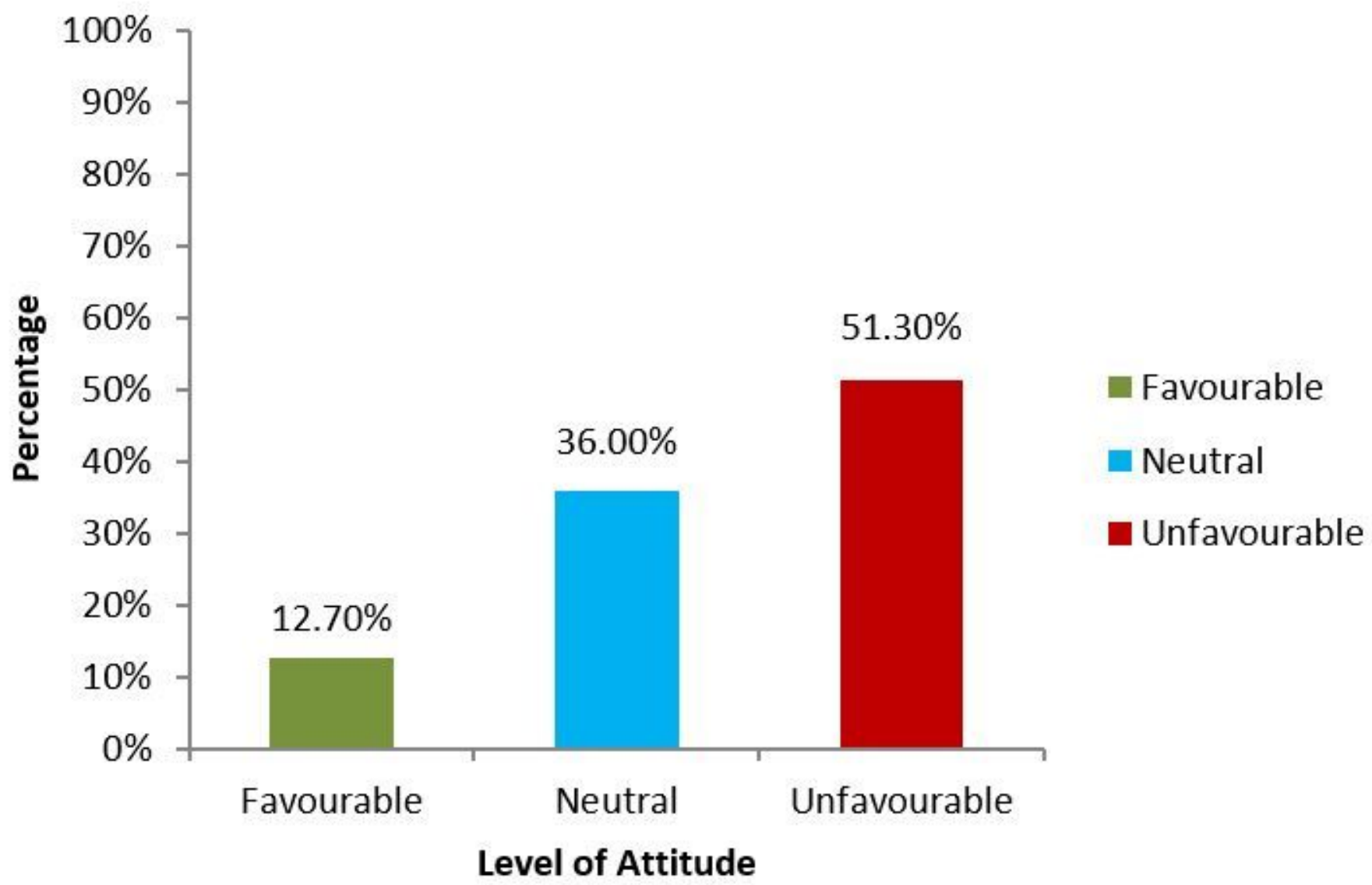

Figure 2

Level of attitude regarding risk factors of CVD among general people

\section{Supplementary Files}

This is a list of supplementary files associated with this preprint. Click to download.

- Questionnaires.docx 